\title{
Subdural hemorrhages in acute lymphoblastic leukemia: case report and literature review
}

\author{
Rui Yin ${ }^{1 *}$, Cai-Xia Qiu², Xiao-Hui Dong ${ }^{3}$ and Ye-Long Chen ${ }^{4}$
}

\begin{abstract}
Background: Acute lymphoblastic leukemia is a rare hematological malignancy. Pure subdural hemorrhages in a patient with acute lymphoblastic leukemia patient are extremely rare.

Case presentation: This case presented acute spontaneous subdural hemorrhage without head trauma at first, and acute lymphoblastic leukemia was diagnosed later. The second time, the patient was admitted with multiple pure subdural hemorrhages in different locations and periods with a history of slight head trauma.

Conclusions: Pure subdural hemorrhages can occur in a patient with acute lymphoblastic leukemia. More care would be needed for pure subdural hemorrhages without obvious head trauma, and patients with hematological malignancies should be protected from even mild head trauma.
\end{abstract}

Keywords: Acute lymphoblastic leukemia (ALL), Head trauma, Hematological malignancy, Subdural hemorrhage (SDH)

\section{Background}

Leukemia, especially acute types, can lead to intracranial hemorrhage (ICH) with high morbidity and mortality $[1,2]$. Chen $\mathrm{CY}$ et al. reported that $\mathrm{ICH}$ occurred in $2.8 \%$ adult patients with hematological malignancies [3]. But the main type of ICH was intraparenchymal hemorrhage, accounted for $74.5 \%$ [4]. Acute lymphoblastic leukemia (ALL) rarely resulted in pure subdural hemorrhage (SDH). This is the first report about several pure SDHs which included two acute types, separately without and with head trauma, and one chronic type in a patient with ALL according to previous literature reports.

\section{Case presentation}

A 63-year-old female who denied any history of head trauma was referred to our hospital with a 2-day slight headache and low-grade fever. She was conscious, and initial physical examination was normal without traumatic clinical manifestations. She denied other histories of diseases but hypertension. Brain computed tomography

\footnotetext{
* Correspondence: neuroyr@163.com

${ }^{1}$ Department of Neurosurgery, Huzhou Central Hospital, NO.198, Hong-qi

Road, Huzhou 313000, Zhejiang Province, China

Full list of author information is available at the end of the article
}

(CT) disclosed acute pure SDH of left frontal-temporal side (Fig. 1).

On the second day, the laboratory data were found abnormal, which included leukocyte count $\left(21.1 \times 10^{9} / \mathrm{L}\right)$, platelet count $\left(36.0 \times 10^{9} / \mathrm{L}\right)$, lymphocyte count $\left(15.7 \times 10^{9} / \mathrm{L}\right)$, D-Dimer $(2.91 \mathrm{mg} / \mathrm{L})$, and the positive plasma protamine paracoagulation test (3P test). Her blood coagulation test was normal. We requested a consultation of hematologist, who performed a bone marrow aspiration. The result suggested that the sum of abnormal lymphocyte accounted for about 61.0 \% (Fig. 2). The diagnosis of ALL was revealed for active hyperplasia of bone marrow tissues, diffuse small lymphocyte and suppressed hyperplasia of granulocytes series, erythroid series and megakaryocyte series.

As hematoma absorbed (Fig. 3) and hypertension controlled, our hematologists enacted a treatment plan for her, but her family rejected and took her to some Shanghai hospital. According to follow-up care, we knew that she underwent a chemotherapy in Shanghai and went back home in a very feeble condition.

About 1 month after her first discharge, she was referred to our hospital again for slight headache with a history of mild head trauma. CT suggested two left SDHs in different locations and periods (Fig. 4). The chronic one was a recurrent kind of hematoma and had 


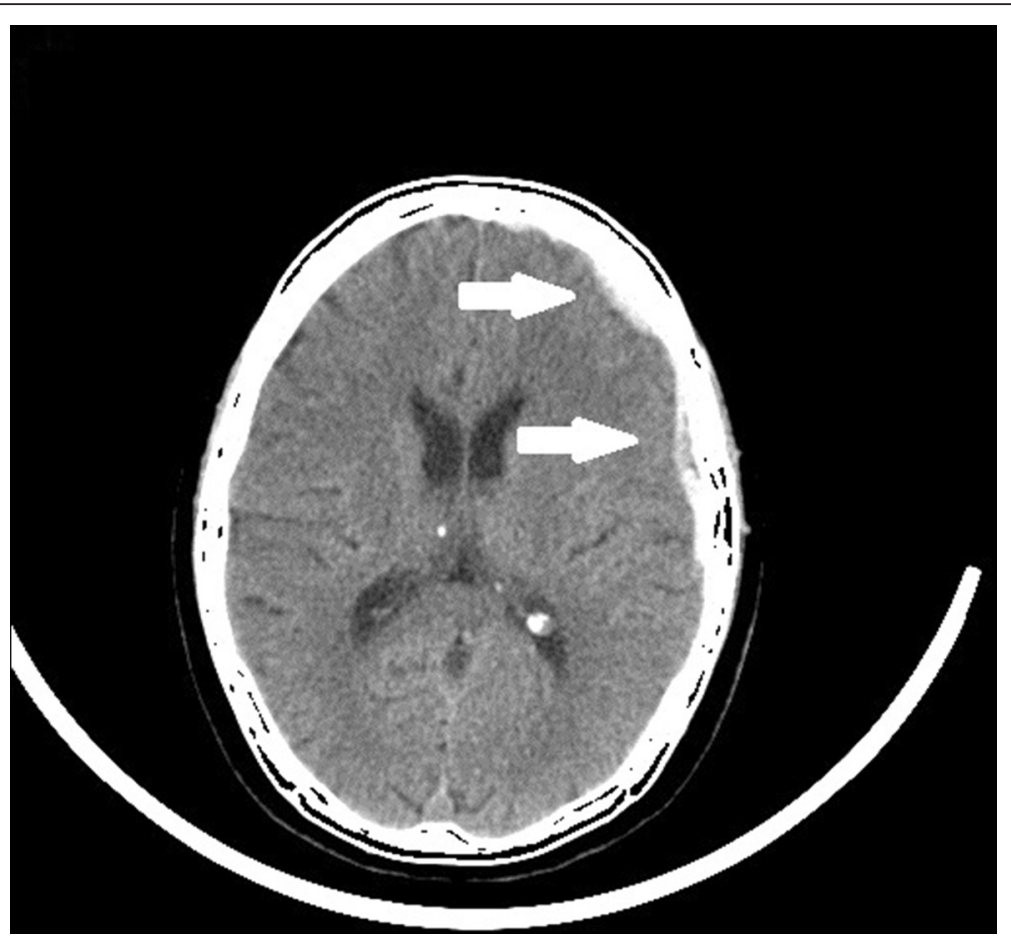

Fig. 1 CT suggested acute pure SDH of left frontal-temporal side in the first hospitalization

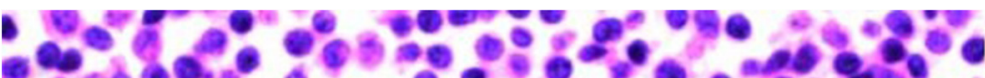

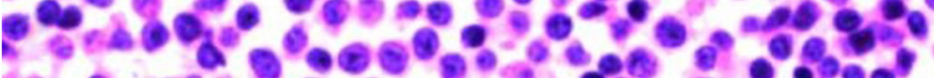

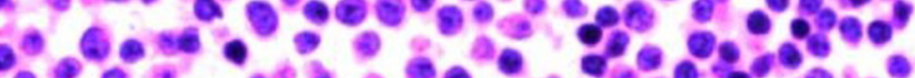

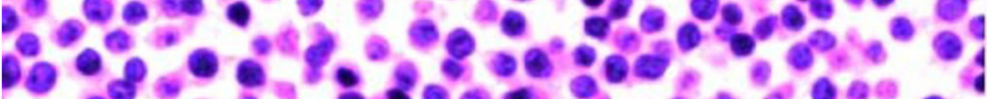
e.6.

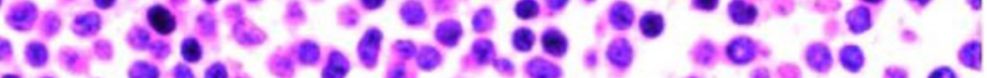

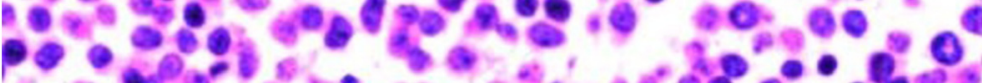

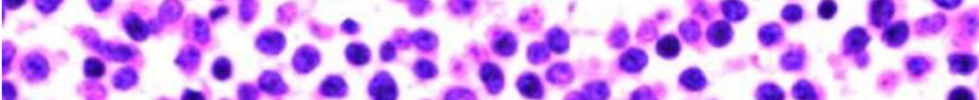

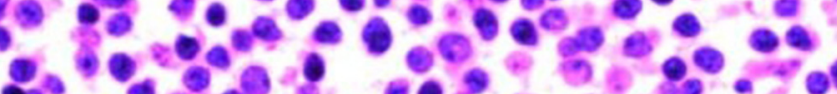

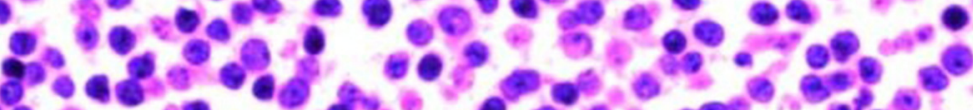

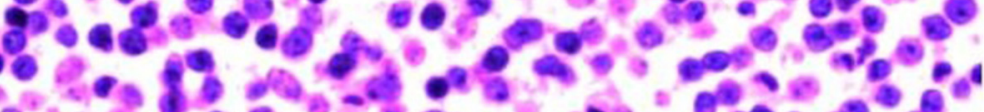

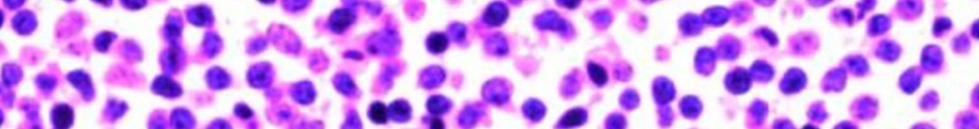

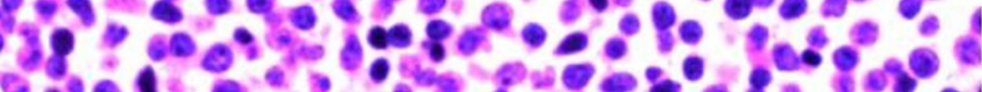

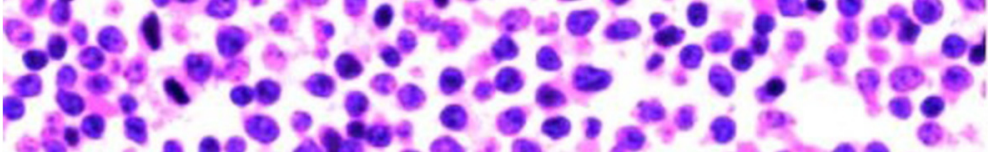
To

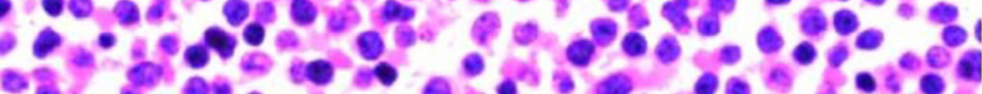
P.

Fig. 2 Pathological analysis of bone marrow suggested increasing abnormal lymphocyte cells 

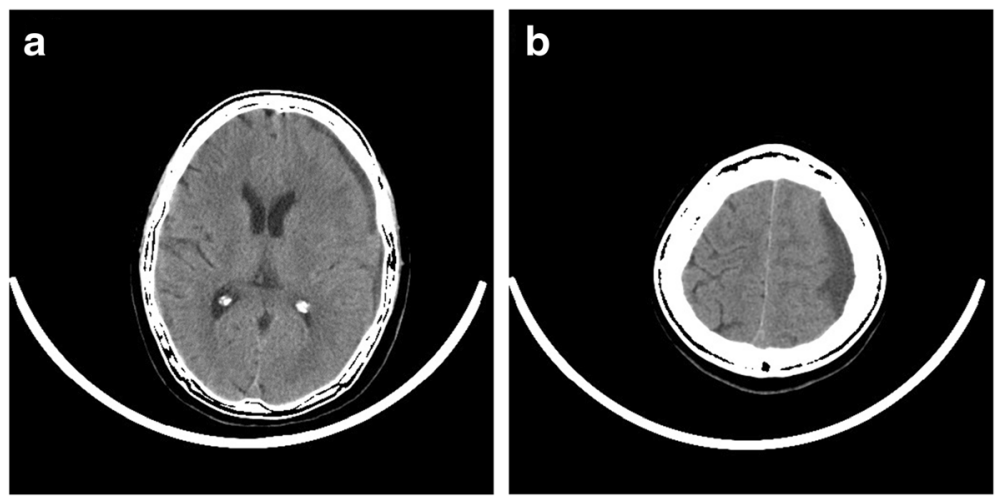

Fig. 3 CT suggested absorbed SDH when the patient was discharged from hospital for the first time. a CT suggested absorbed SDH of left frontal-temporal side in the first hospitalization. $\mathbf{b}$ CT suggested absorbed SDH of left parietal side in the first hospitalization

a relationship with her first acute SDH which had been absorbed completely.

Leukocyte count $\left(153.9 \times 10^{9} / \mathrm{L}\right)$, platelet count $(6.0 \times$ $\left.10^{9} / \mathrm{L}\right)$, lymphocyte count $\left(20.0 \times 10^{9} / \mathrm{L}\right)$, D-Dimer $(6.98 \mathrm{mg} / \mathrm{L})$, and erythrocyte count $\left(1.97 \times 10^{12} / \mathrm{L}\right)$ revealed aggravated condition. Fecal occult blood was positive with $(+)$. The blood coagulation test was normal again. In addition to the symptomatic treatments, we advised specialized therapy of department of hematology, but her families rejected again. 1 month later, the patient died of multiple organ dysfunction syndrome (MODS) after long-term unconsciousness.

\section{Discussion}

This case had repeated SDHs. The first one was acute and spontaneous without definite history of head trauma. The second time, she had two SDHs in different locations, which included an acute type and an unaware chronic type. These were all pure SDHs, which was very rare. In the study of Chen CY [3], the incidence of pure

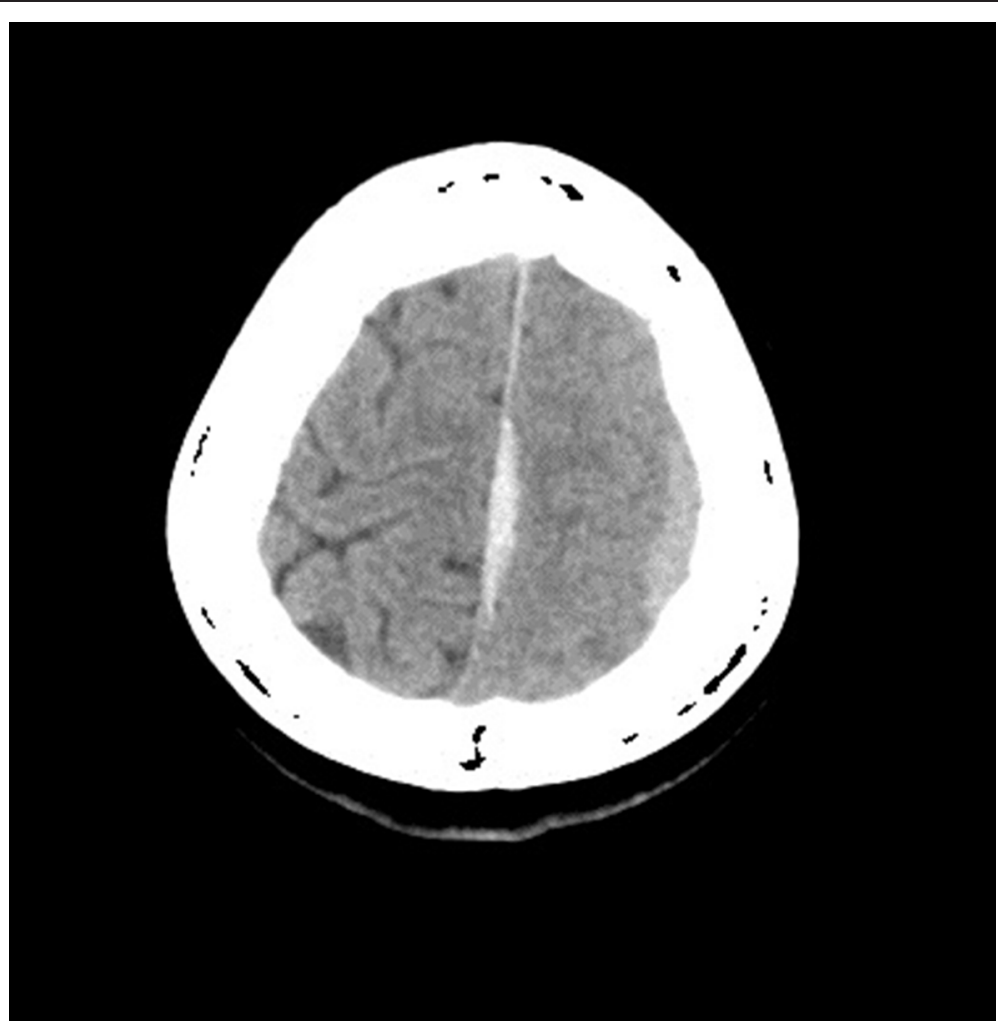

Fig. $4 \mathrm{CT}$ suggested two left SDHs in different locations and periods in the second hospitalization 
$\mathrm{SDH}$ was $0.47 \%$ in patients with hematological malignancies. But repeated pure SDHs in ALL were never reported.

For tearing of the bridging and cortical veins, SDH could occur. Acute SDH often has a clear history of head trauma. Chronic SDH usually occurs after 3 weeks or even a longer time so that the history of head trauma may be forgotten. But in the patients with hematological malignancies, head trauma may be not a necessary cause, which was also proved through our case.

The possible risk factors of $\mathrm{ICH}$ caused by leukemia include thrombocytopenia, platelet dysfunction, disseminated intravascular coagulation (DIC), coagulation factor deficiency, hyperleukocytosis, vessel wall abnormalities, hypertension and sepsis [2, 4]. Our patient had thrombocytopenia all the time. ALL was getting worse that could be found in her laboratory data. The D-Dimer was getting higher, 3P tests were positive and fecal occult blood was positive with $(+)$, which all revealed aggravated DIC.

Yhim HY et al. reported bilateral chronic subdural hemorrhage as a serious adverse event of dasatinib in a patient with Philadelphia chromosome-positive acute lymphoblastic leukemia [5]. Our patient had no chance of chromosome examination, but the clinical manifestations of her first acute SDH and the second chronic $\mathrm{SDH}$ were similar to that case. This may suggest the evolution of SDH in ALL patients even without dasatinib, that acute SDH in ALL may have a strong tendency to develop chronic SDH.

This patient had repeated SDHs without serious central nervous system involvement or surgery. This did not mean insignificant condition. Previous study had shown high mortality (50 \%) among SDH patients with hematological malignancies [5]. Each $\mathrm{SDH}$, caused by hematological malignancy, may be also associated with a higher possibility of neurosurgery and potential adverse outcomes.

So far, there is still no effective way to prevent $\mathrm{ICH}$, including SDH, in patients with hematological malignancies. Prophylactic platelet transfusions to maintain the platelet count at a safe threshold has been proved to be an effective treatment to decreased the risk of hemorrhagic complication with hematological malignancies [6]. Considering the etiology of SDH, ALL patients should also be protected from even mild head trauma through our case.

\section{Conclusion}

Various types of pure SDHs in a patient with ALL are extremely rare. Acute pure SDH can occur in ALL patients without definite head trauma. Even if acute SDH was absorbed completely, secondary unaware chronic SDH could occur. Homonymous acute SDH and chronic
SDH in different locations could coexist in ALL. Hematological malignancies should be considered when a patient, who had no obvious history of head trauma, came with acute SDH and low-grade fever. With the aggravation of ALL, worse laboratory data may suggest higher risk of chronic SDH after acute SDH. In addition to active diagnosis and treatment, ALL patients should be protected from even mild head trauma to avoid SDH for their tendency of hemorrhage.

\section{Abbreviations}

ALL, acute lymphoblastic leukemia; CT, computed tomography; DIC, disseminated intravascular coagulation; ICH, intracranial hemorrhage; SDH, subdural hemorrhage

\section{Acknowledgements}

The authors wish to thank Yuan-Li Zhao MD, Professor, in the Department of Neurosurgery, Beijing Tiantan Hospital, Capital Medical University, Beijing, China, for his support and enthusiasm.

Funding

This research received no specific grant from any funding agency in the public, commercial, or not-for-profit sectors.

Availability of data and materials

The manuscript does not include any new software, databases or all relevant raw data.

\section{Authors' contributions}

RY and CXQ contributed to write the report. RY, CXQ and XHD contributed in clinical treatment of the case. RY contributed in drafting the manuscript. $\mathrm{RY}$ and YLC contributed in revising the manuscript. All authors read and approved the final manuscript.

\section{Competing interests}

The authors declare that they have no competing interests.

\section{Consent for publication}

This case report has had consent to publish with our institutional consent form signed by her family members.

Ethics approval and consent to participate

The manuscript has had ethics approval and consent to participate by medical ethics committee of Huzhou Central Hospital.

\section{Author details}

'Department of Neurosurgery, Huzhou Central Hospital, NO.198, Hong-qi Road, Huzhou 313000, Zhejiang Province, China. ${ }^{2}$ Department of Neurology, Huzhou Central Hospital, NO.198, Hong-qi Road, Huzhou 313000, Zhejiang Province, China. ${ }^{3}$ Department of Hematology, Huzhou Central Hospital, NO.198, Hong-qi Road, Huzhou 313000, Zhejiang Province, China. ${ }^{4}$ Department of Pathology, Huzhou Central Hospital, NO.198, Hong-qi Road, Huzhou 313000, Zhejiang Province, China.

Received: 31 January 2016 Accepted: 27 July 2016

Published online: 18 August 2016

\section{References}

1. Dayyani F, Mougalian SS, Naqvi K, Shan J, Ravandi F, Cortes J, et al. Prediction model for mortality after intracranial hemorrhage in patients with leukemia. Am J Hematol. 2011;86:546-9.

2. Kim H, Lee JH, Choi SJ, Lee JH, Seol M, Lee YS, et al. Risk score model for fatal intracranial hemorrhage in acute leukemia. Leukemia. 2006;20:770-6.

3. Chen $\mathrm{CY}$, Tai CH, Cheng A, Wu HC, Tsay W, Liu JH, et al. Intracranial hemorrhage in adult patients with hematological malignancies. BMC Med. 2012;10:97.

4. Chen CY, Tai CH, Tsay W, Chen PY, Tien HF. Prediction of fatal intracranial hemorrhage in patients with acute myeloid leukemia. Annals of Oncology. 2009;20:1100-4. 
5. Yhim HY, Kim HS, Lee NR, Song EK, Kwak JY, Yim CY. Bilateral subdura hemorrhage as a serious adverse event of dasatinib in a patient with Philadelphia chromosome-positive acute lymphoblastic leukemia. Int J Hematol. 2012:95:585-7.

6. Blajchman MA, Slichter SJ, Heddle NM, Murphy MF. New strategies for the optimal use of platelet transfusions. Hematology Am Soc Hematol Educ Program, 2008, 198-204. doi:10.1182/asheducation-2008.1.198.

Submit your next manuscript to BioMed Central and we will help you at every step:

- We accept pre-submission inquiries

- Our selector tool helps you to find the most relevant journal

- We provide round the clock customer support

- Convenient online submission

- Thorough peer review

- Inclusion in PubMed and all major indexing services

- Maximum visibility for your research

Submit your manuscript at www.biomedcentral.com/submit 